$\xi=-1$

\title{
Traffic Management at Madhya Kailash Intersection along Rajiv Gandhi Road in Chennai
}

\author{
Sampathkumar. $\mathbf{V}^{1 *}$, Samuel Simron Rajkumar², \\ ${ }^{1,2}$ Department of Civil Engineering, Sathyabama Institute of Science and Technology, Chennai. \\ *Corresponding author E-mail :svsjpr@gmail.com
}

\begin{abstract}
This paper focuses on the improvement of the traffic flow at the three-major congested intersection located near Madhya Kailash, Tidel Park and SRP Tools along Rajiv Gandhi road in Chennai City. Road inventory survey and volume count survey have been conducted at the three intersections. Volume accumulation curves are developed to obtain the peak volume and peak time. From the analysis it is found that the peak volume is about 2321 passenger car equivalence (PCE), 2544 PCE and 2396 PCE at the three intersections respectively during peak hour. The volume to capacity ratio is about 1.29, 1.41 and 1.33 obtained which makes high level of congestion and poor level of service in turn shows an immediate need of traffic management measure. Transport system management concepts are suggested to manage the traffic flow which will improve the flow at the study intersections.
\end{abstract}

Keywords: Use about five key words or phrases in alphabetical order, Separated by Semicolon.

\section{Introduction}

Traffic congestion is a condition on transport networks that occurs as use increases, and it is characterized by slower speeds, longer trip times and increased vehicular queuing. When vehicles are fully stopped for a period of time, called as a traffic jam. Generally on poorly planned road network, a common outcome is the presence of hotspots which are subjected to congestion. Rapid growth in volume of vehicles and inadequate traffic management around the hotspots are fundamental factors which lead to traffic congestion. Chennai is the gateway of South East Asia, and act as a backbone of economy of National development. Chennai is being the fastest growing city with a road length of $2780 \mathrm{~km}$ (The state level committee ${ }^{1}$ ) in radial and ring pattern. It had $4.40 \mathrm{~L}$ jobs in the year 2011 and witnessing a growth of $9 \%$ per year, by the Employment Trends Survey.

The first $20 \mathrm{~km}$ of the Rajiv Gandhi road between Madhya Kailash and Siruseri, has been the biggest growth engine for Chennai city. It provides jobs for more than 2 Lakh Information Technology (IT) professionals and it is expected to grow by another one lakh in the coming years. Since 2005, much people have moved into Rajiv Gandhi road. It becomes an alternative residential hub also. The volume of traffic on the IT corridor is more than 5 Lakh vehicles on weekdays. The duration of rush hour traffic has extended to 3 hours each in the morning and evening. Personalized modes dominate upto $60 \%$ on road in which two-wheeler contribution is more than $50 \%$. In 2016, there were 35 fatal accidents and 194 non-fatal accidents on Rajiv Gandhi road, the road witnessed 3 to 4 accidents every day (The Hindu, Deepa H Ramakrishnan $^{2}$ ) making the travel a worst-case scenario. Residents and employees of firms have been waiting for more than two years for road improvements.
The Hindu, Oppili ${ }^{3}$ said that the traffic on Sardar Patel road, near Madhya Kailash, Adyar, and Taramani road, was disrupted many hours after a concrete mixer truck overturned. The accident and resultant pile-up highlights the need for better traffic management system on this congested stretch. Thousands of vehicles use the stretch every day, especially after the advent of the IT corridor and the MRTS line. Regular road users hope that the work to widen Tarmani road- Rajiv Gandhi road will proceed faster and pedestrian crossings would be marked on the Taramani Road. Manuj Darbari et $\mathrm{al}^{4}$ discussed the application of Petrinet as the workflow tool to model urban traffic system. Their paper was divided into two phase. The first phase dealt with orthogonal extension of Petrinet to enhance the permutation of control and traffic flow simulation and the second phase discussed the application of continuous pertinent with intelligent agents to the model the urban traffic system in continuous format with single central control agent.

Bhargavi P.S and N. Kannaiya Raja ${ }^{5}$ studied the reasons for road traffic accidents in Tamilnadu. Also they investigated the different causes of accidents occurred in past years. Tamilnadu was reported in one of the accident prone zone in India with having highest rate of road accidents. Amudapuram Mohan Rao and Kalaga Ramachandra $\operatorname{Rao}^{6}$ reviewed based on measurement metrics such as speed, travel time, delay, volume and level of service. The review covered distinct aspects such as measurement criteria of different countries and organizations. The strength and weakness were discussed. Takayuki Kishii ${ }^{7}$ discussed the utilization of underground space in Japan. The classification of underground space was indicated and then the utilization of underground space under private lands and public lands was explained.

Absar Alam.M and Faisal Ahmed ${ }^{8}$ discussed the traffic scenario in selected Asian cities and the policy measures undertaken by their respective governments. They explained relevant policies in India and assessed the gaps that deter the desired impact of such policies on reducing traffic congestion and suggested the policy measures 
to overcome the gaps. Jian Sheng Yeung and Yiik Diew Wong ${ }^{9}$ said that in rapidly growing economies with limited land space, underground road tunnels were becoming more prevalent. Before the implementation of large-scale underground road systems, it was necessary to garner more knowledge on their implications and impacts. Their study examined 608 road traffic accidents which occurred on three Singapore expressway tunnels between 2009 and 2011. Aparajita Chakrabartty and Sudakshina Gupta ${ }^{10}$ discussed about the high population density in Kolkata. The road space in Kolkata was only $6 \%$. High demand for mobility coupled with low road space lead to high congestion on the roads. The authors tried to measure congestion on a few arterial roads of Kolkata through a congestion or mobility index. Sampathkumar V et $\mathrm{al}^{11}$ studied the intersection improvement at Sholinganallur in Rajiv Gandhi road and suggested a short and long term measures. As a short term measure, restricting the right turn movements, diverting 2 and 4 wheelers to alternate routes to reach Siruseri without passing through the study intersection was suggested. As a long term measure, a grade separator along the centre of road toward north and south would reduce the volume at intersection. Transportation systems management (TSM) concepts would reduce the level of congestion and this type of studies would help to manage the traffic flow in an economical way.

Tadashiltoh $^{12}$ discussed about $28 \mathrm{~km}$ Mittlerer ring which was constructed in 1972 Olympics. Construction of the underground tunnels was implemented for Mittlerer ring in the 1980s to improve the habitation environment. He studied the effect of the underground tunnels of Mittlerer ring. The change of land prices along Mittlerer ring and in the Munich area from 1980 to 2010 was observed. Then, by creating a land price function for every 10 years from 1980 to 2010 , the change by the effect of the tunnel was examined, and the benefits of the tunnels were estimated. Land price along Mittlerer Ring were found to be much lower than that in other areas in 1980. Thus, tunnel construction might increase land price not only along streets with tunnels but also along the entire Mittlerer ring. Dimitris Kaliampakos et $\mathrm{al}^{13}$ attempted to enlighten the trends of the modern underground industry and furthermore, reviewed the construction cost levels for various infrastructure types and discussed the economic benefits of underground structures were latent and were associated with social and environmental externalities. YangYang et $\mathrm{al}^{14}$ studied a case of urban underground ring road in Chongqing, China was analyzed using the established model in order to find the most effective way to improve the evacuation capacity. TNN Updated ${ }^{15}$ reported that even after a new traffic signal between Madhya Kailash and Tidel Park, on Old Mahabalipuram road (OMR), came into operation, residents using the stretch deeply disappointed. Though it was a four-way signal, it did not allow entry from both Indira Nagar on eastern side of OMR and Kaanagam on western side of OMR. Uturn for motorists coming from Madhya Kailash was not permitted. The review of literature reveals the methods of operational improvement and its importance.

\section{Study Area}

Rajiv Gandhi Road (State Highway 49A) early it was named as OMR, is a major road connecting Chennai with Mahabalipuram in Kanchipuram district of Tamilnadu. It is $45 \mathrm{~km}$ long and the road starts from Madhya Kailash temple on Sardar Patel road in South Chennai and terminates near Mahabalipuram on East Coast road. Tidel Park, many numbers of business process outsourcing and IT and IT Enabled Service companies and State Industries Promotion Corporation of Tamil Nadu Limited (SIPCOT) in Siruseri are situated along this road. Many technical and educational institutions are also located on the same corridor. Rajiv Gandhi road is having nine major intersections located near Madhya Kailash, Tidel Park, SRP Tools, Perungudi, Thoraipakkam, Sholinganallur, Navalur, Siruseri and at Kelambakkam. Out of nine intersections the maximum congestion and delay occurred at Madhya Kailash, Tidel park intersection and at SRP Tools intersection which is taken as study area. It is a highway with six lane and its width is $25 \mathrm{~m}$ and $5.6 \mathrm{~km}$ long. During 17.00 to 21.00 hours the volume of vehicle flow is very high. It takes about 25 minutes to travel for about $4.1 \mathrm{kms}(9.84 \mathrm{kmph})$ during this time period. The inter distance between Tidel park to SRP Tools is $1.5 \mathrm{kms}$ which is shown in Figures 1 and 2, the geomentry of study road is shown in Figure 3 and the photographs taken at three intersections are shown in Figures 4,5 and 6.

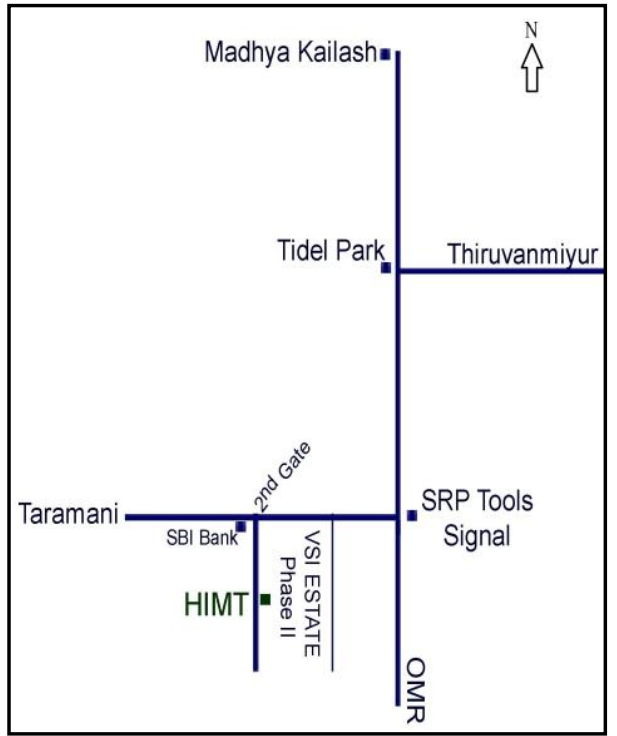

Fig. 1 Study road route map between Madhya Kailash and SRP Tools intersection

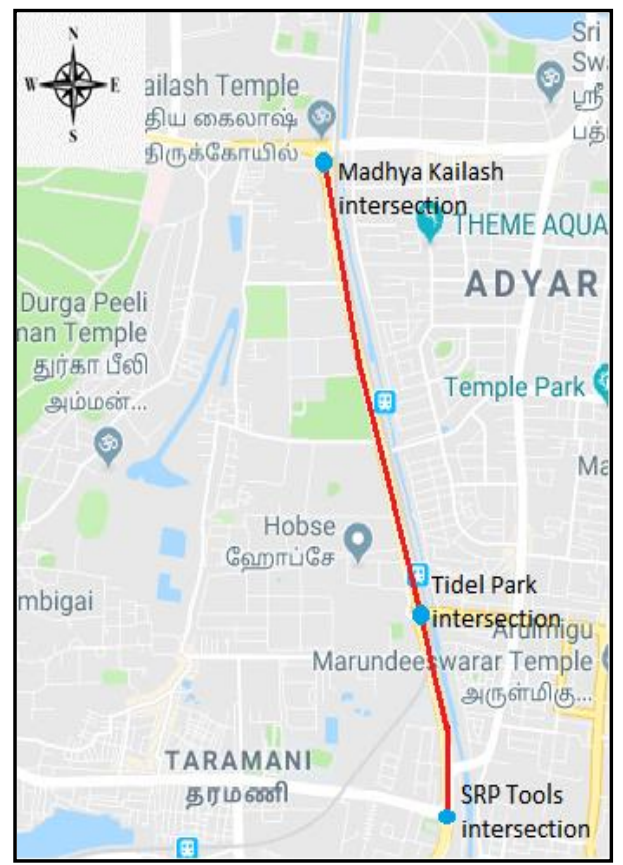

Fig. 2 Study road between Madhya Kailash and SRP Tools intersection 


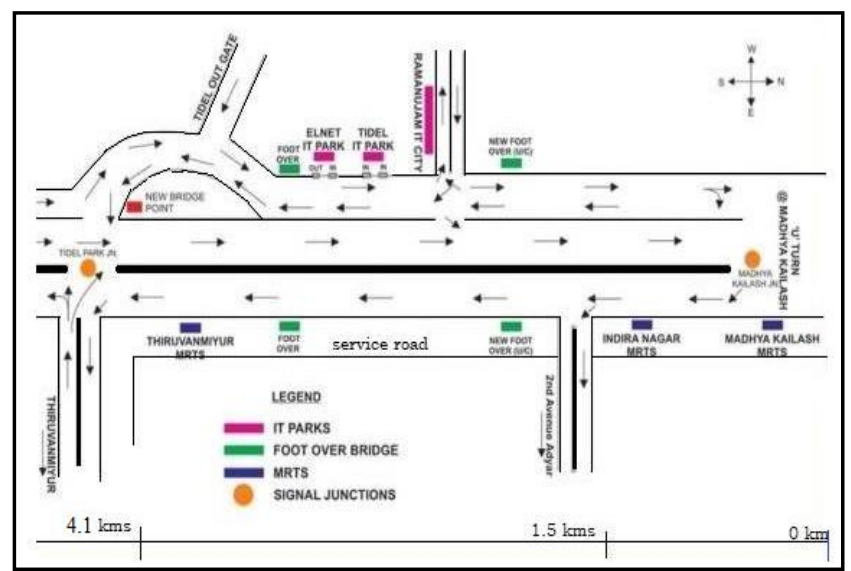

Fig. 3 Geomtry of study road between Madhya Kailash and SRP Tools

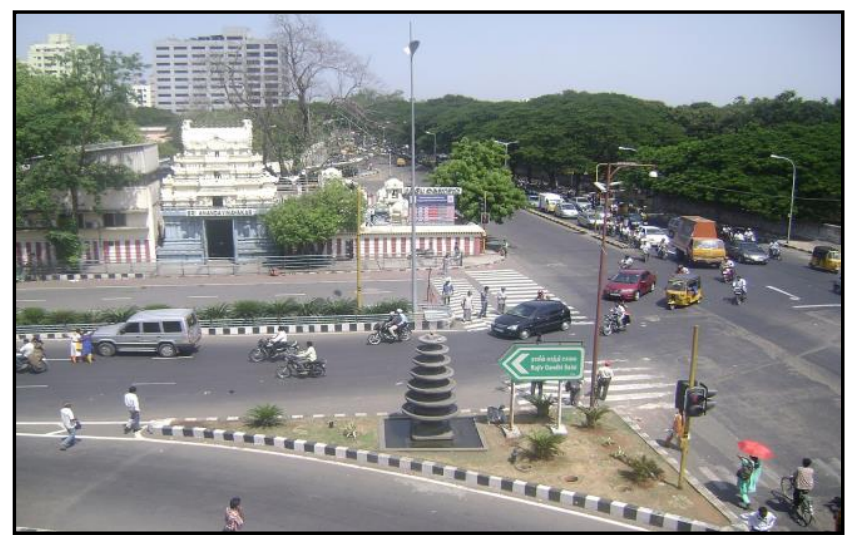

Fig. 4 Madhya Kailash intersection along Rajiv Gandhi road

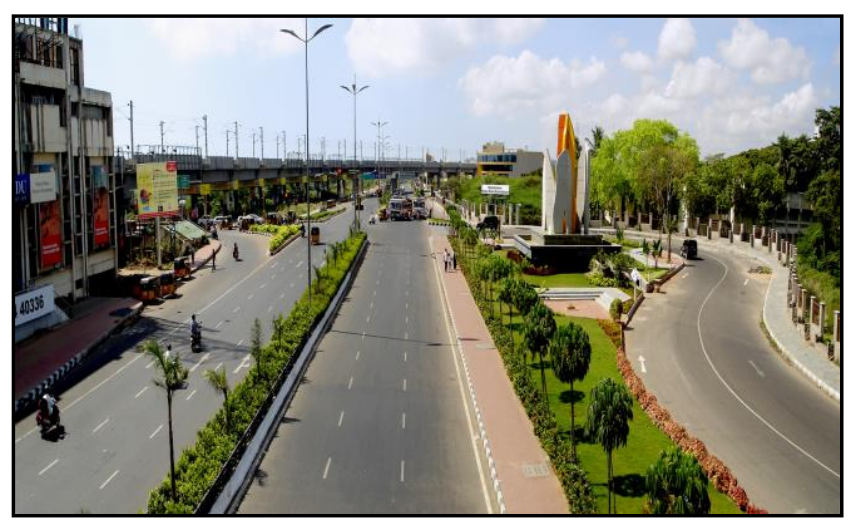

Fig. 5 Tidel park intersection along Rajiv Gandhi road

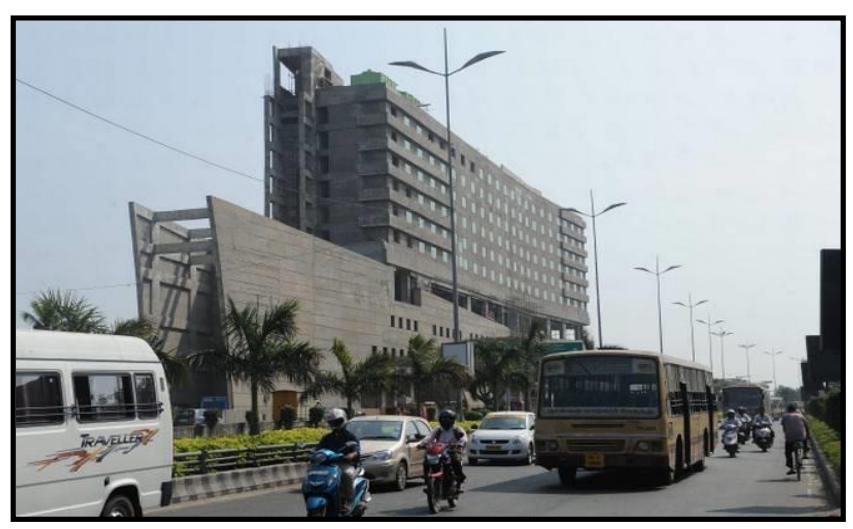

Fig. 6 SRP Tools intersection along Rajiv Gandhi road

\section{Data Collection}

Road geometric survey and traffic volume study are conducted to determine the volume, movements and the composition of roadway vehicles at the three selected intersections. These data can help to identify the peak flow hour, peak volume and to determine the influence of huge vehicle volume on pedestrian movement. A continuous manual volume count have been conducted and the obtained traffic volume data is converted into passenger car equivalence (PCE) to bring various vehicles into a single unit using conversion factor as per Indian Road Congress (IRC-1061990) specification. The vehicle volume trend between $8 \mathrm{hrs}$ and 22 hrs at three intersections are shown in Figures 7, 8 and 9 respectively. The peak flow occurs between 17.30-18.30 hrs at Madhya kailash intersection (2321 PCE) and the same occur between 20-21 hrs at other two intersections (2544 PCE at Tidel park and 2396 PCE at SRP Tools).

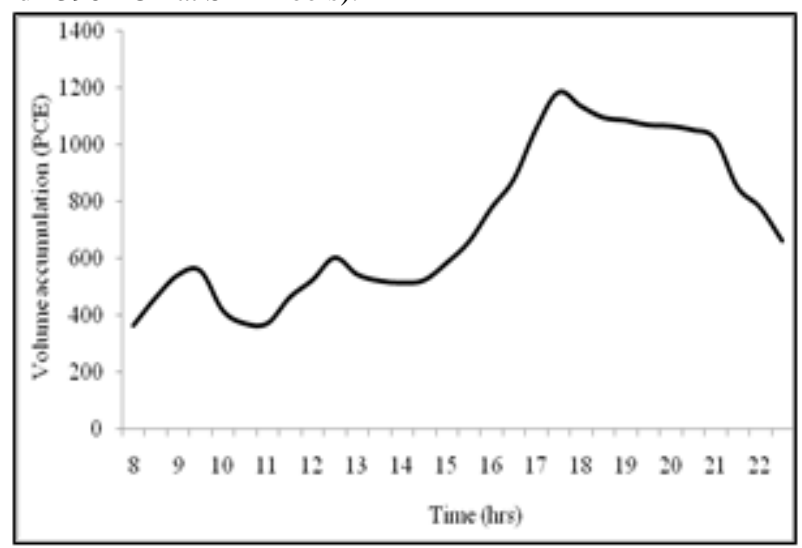

Fig. 7 Volume accumulation in PCE at Madhya Kailash intersection

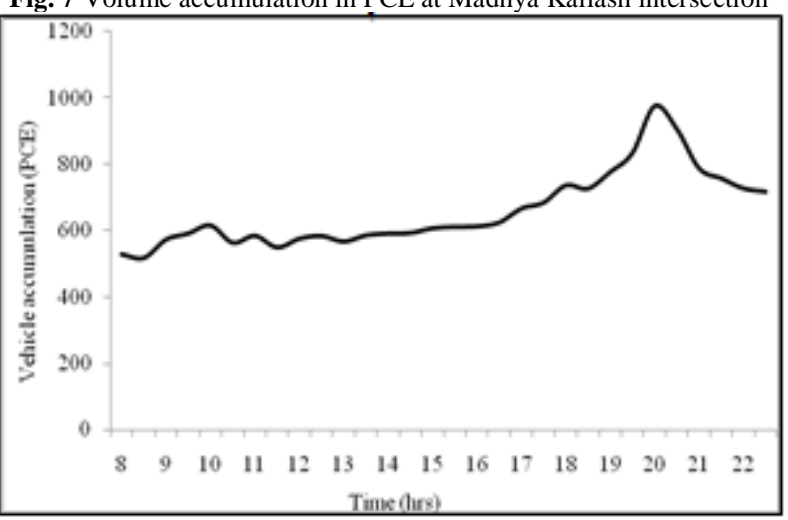

Fig. 8 Volume accumulation in PCE at Tidel park intersection

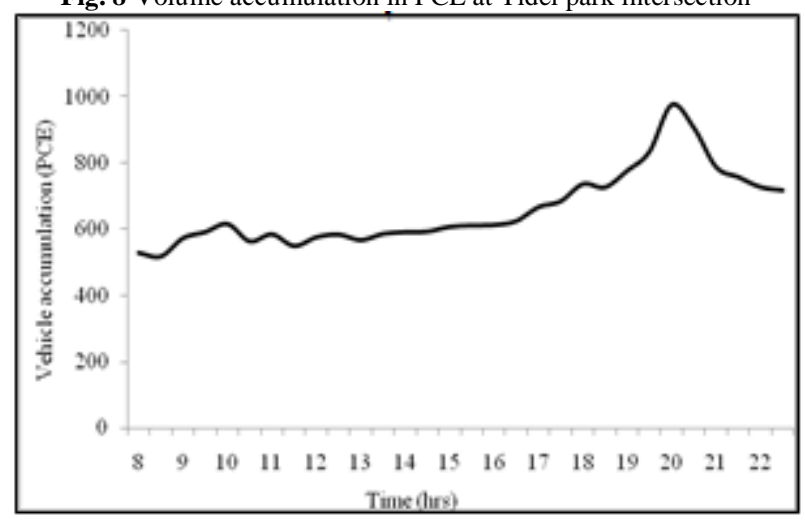

Fig. 9 Volume accumulation in PCE at SRP Tools intersection

The composition of vehicles at peak hour flow at three intersections are shown in Figures 10, 11 and12 which implies that the domination of two wheelers is more than $60 \%$ and the combination of cars and two wheelers are more than $90 \%$. The volume split occurred at peak hour in the three intersections is shown in Figures 13, 14 and15. The practical capacity of all purpose roads with high volume junction where no standing vehicles are allowed 
on a multi-lane two-way urban road is 1800 PCE. Here the volume to capacity ratio is tabulated in Table 1 which implies at all three intersections $\mathrm{V} / \mathrm{C}$ are greater than one, which need immediate improvement measure to improve the flow.

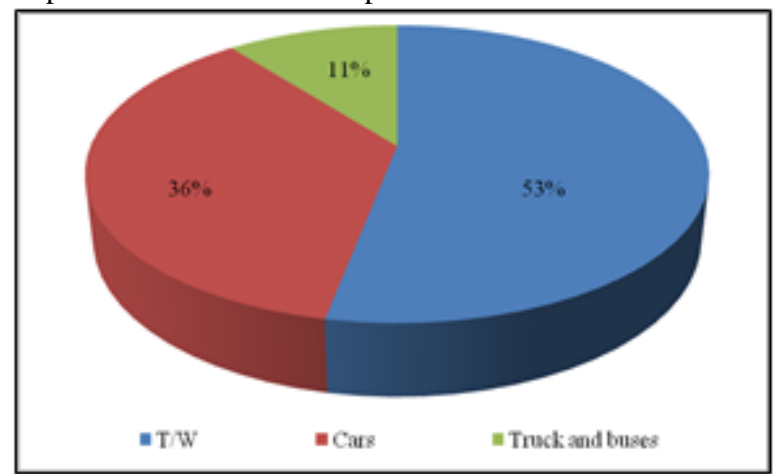

Fig. 10 Vehicle composition at Madhya Kailash intersection (17.30-18.30 hrs)

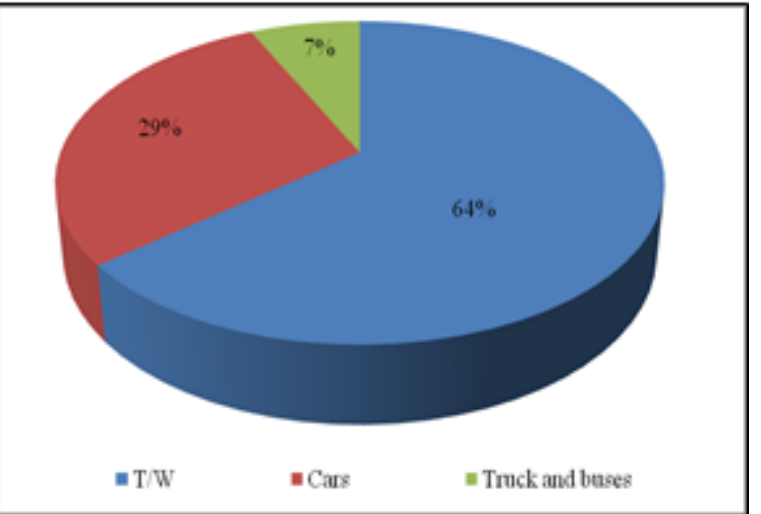

Fig. 11 Vehicle composition at Tidel Park intersection (20.00-21.00 hrs)

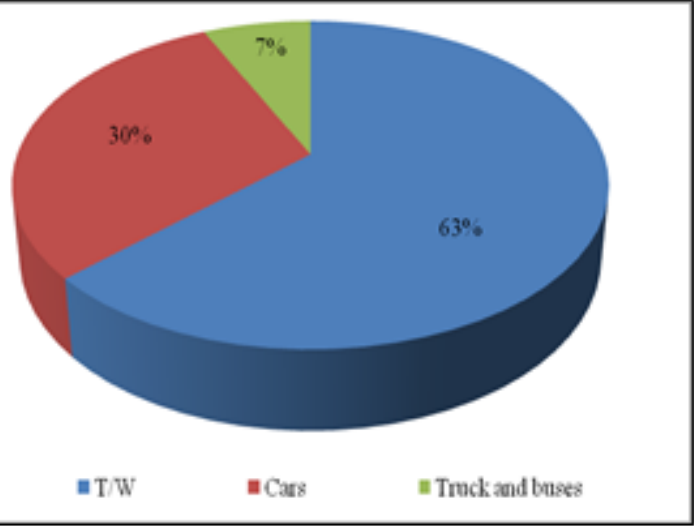

Fig. 12 Vehicle composition at SRP Tools intersection (19.00-20.00 hrs)

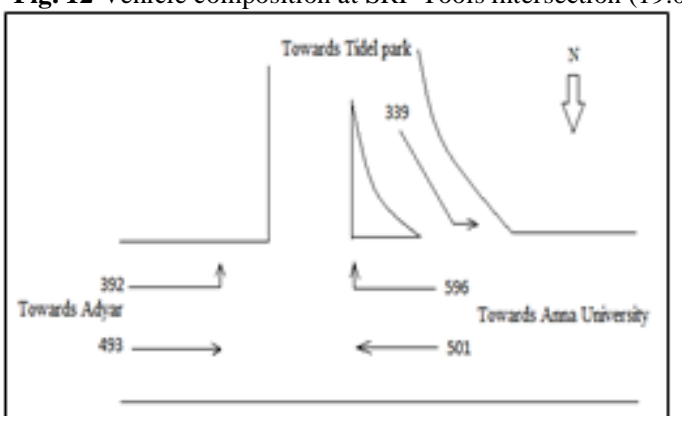

Fig. 13 Traffic volume in PCE at peak hour (17.30-18.30 hrs) in Madhya Kailash intersection

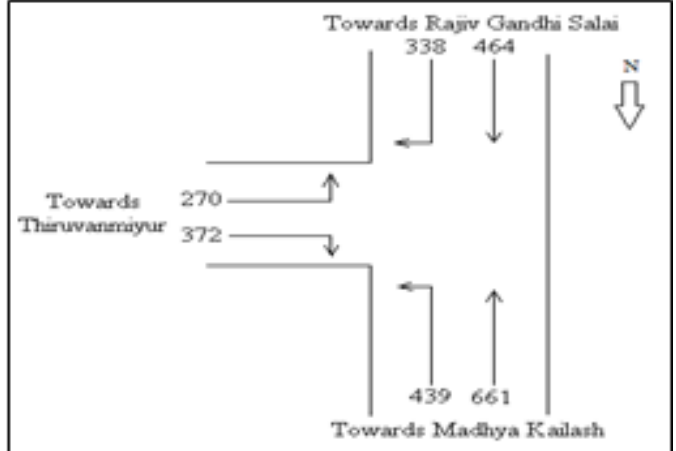

Fig. 14 Traffic volume in PCE at peak hour (20.00-21.00) in Tidel park intersection

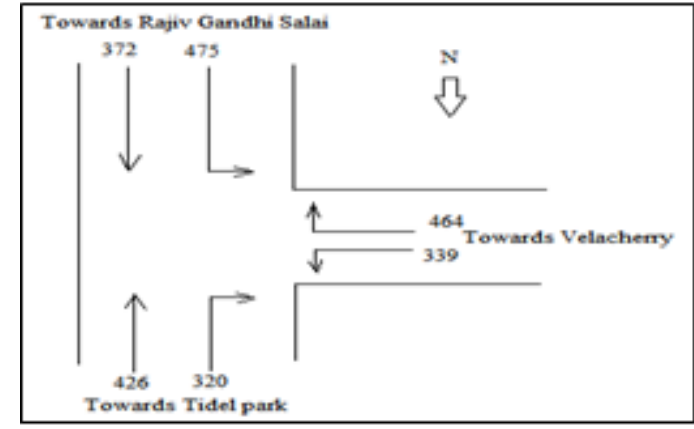

Fig.15 Traffic volume in PCE at peak hour (20.00-21.00) in SRP Tools intersection

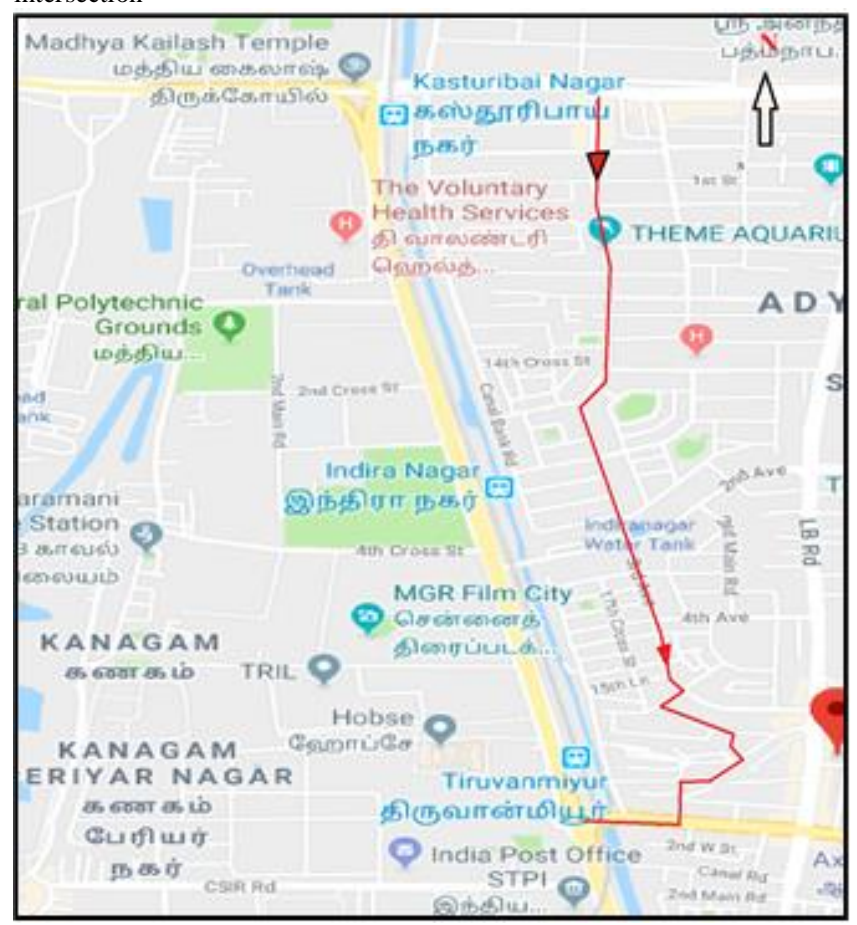

Fig.16 Proposed alignment from Sardar Patel road to Rajiv Gandhi road 


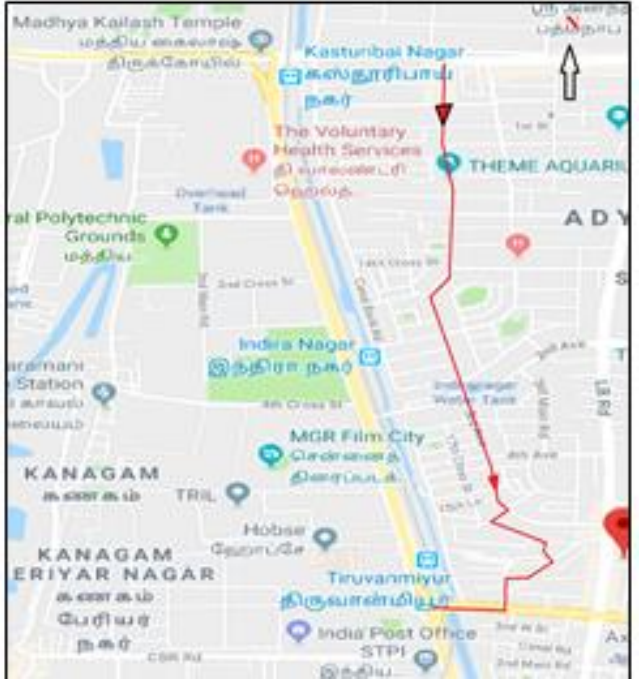

Fig. 17 Alternate route between Madhya Kailash and Tidel park intersections

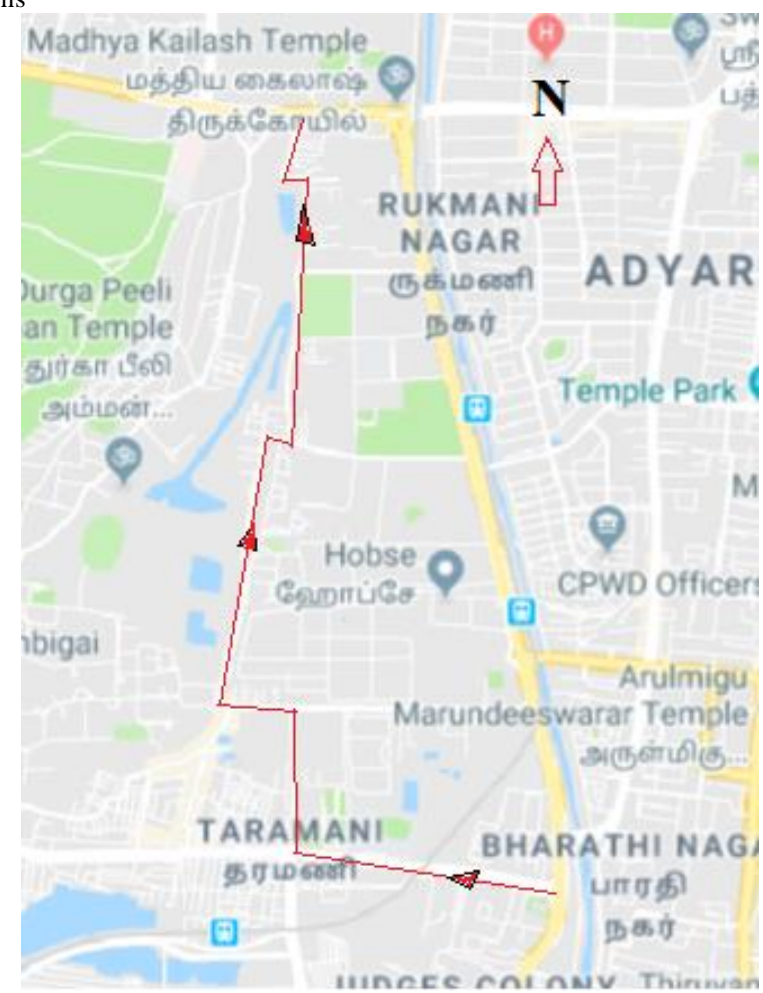

Fig. 18 Alternate route between SRP Tools intersection and Sardar Pate road

Table 1: Volume to capacity ratio at the study intersections

\begin{tabular}{|c|l|c|c|c|}
\hline No. & Intersection & $\begin{array}{c}\text { Volume (V) } \\
\text { in PCE }\end{array}$ & $\begin{array}{c}\text { Capacity (C) } \\
\text { in PCE }\end{array}$ & V/C \\
\hline 1 & Madhya kailash & 2321 & 1800 & 1.29 \\
\hline 2 & Tidel park & 2544 & 1800 & 1.41 \\
\hline 3 & SRP Tools & 2396 & 1800 & 1.33 \\
\hline
\end{tabular}

Source : For capacity ref: Table 21.19 Practical capacities of twoway Urban roads, p535, Chapter 21, Section 11, Highway capacity, "Traffic engineering and transportation planning" by L.R.Kadiyali, Khanna publishers, $8^{\text {th }}$ Edition 2013, ISBN 81-7409-220-X.

\section{Traffic Management at Study Area}

As a short term measure it may not be necessary for all vehicles to take the secondary alternative route and it can be more profitable. Tidel Park and SRP Tools intersections can be reached in lesser time using alternative routes at least during the peak hours instead travelling on Rajiv Gandhi road. From Wikipedia ${ }^{16}$ as a long term measure, a trumpet interchange was proposed at Madhya kailash intersection by TNRDC. The proposed interchange was supposed to start at the Rajiv Gandhi road in front of Kasturibai Nagar railway station and go parallel to MRTS line and then turn about while splitting into two, joining Sardar Patel road. In 2007, the Secretary to the Highways Department clarified that this proposal had been rejected by the State Government - as it felt land acquisition would be a problem and the facility could possibly be a disturbance to educational institutions located nearby. The Indian Institute of Technology, Anna University and the State Highways department engineers had presented three independent project proposals for easing traffic congestion. As of December 2007, the Chennai City Corporation and the state Government were yet to finalize the design and alignment of the flyover. As an alternate to this proposal the existing flyover from Gandhi Mandapam on Sardar Patel road can be extended up to Madhya Kailash and it may descends on Rajiv Gandhi road towards South will drags the peak volume to 1725 PCE and the volume to capacity will come down to 0.95 which helps to decongest this intersection which is shown in Figure 16.

As a short-term management measure, by introducing a $\mathrm{T}$ turn at Madhya Kailash intersection will further drags 392 PCEs and the peak volume will comes down to 1333 PCE . Diversion of the flow towards south at the Madhya Kailash intersection has to turn south in the before point near Adyar student Xerox and runs through first avenue, eighth avenue, $28^{\text {th }}$ and $29^{\text {th }}$ cross streets and enters to ECR near Poondiamman koil to reach Tidel park. These local streets have a width above $7 \mathrm{~m}$ which can accommodate oneway movement of vehicles which is shown in Figure 17. As a further management measure, by diverting the vehicles towards North at SRP Tools intersection, to the West via Tharamani road to reach Sardar Patel road will bring down 372 PCE at the specified intersection and the peak volume will become 2024 PCE. The diverted traffic via Tharamani road has to pass through VV Koil street towards North, CSIR road towards West, Pillaiyar koil street towards North, Kalikunram main road towards North, Pallipattu main road towards North and Sriram Nagar main road towards North to reach Sardar Patel road. The alternate route between SRP Tools intersection and Sardar Patel raod is shown in the Figure 18. The long and short term management measures at Madhya Kailash Tidel park and SRP Tools intersection will improve the flow of vehicles and will sustain at least for the next couple of years along Rajiv Gandhi road.

\section{Conclusion}

Traffic congestion is a condition on transport networks that occurs as use increases, and it is characterized by slower speeds, longer trip times, and increased vehicular queuing. Rapid growth of vehicles volume and inadequate traffic management around the hotspots are fundamental factors which lead to traffic congestion. The first $20 \mathrm{~km}$ of the Rajiv Gandhi road between Madhya Kailash and Siruseri, has been the biggest growth engine for Chennai city. Many technical and educational institutions are also located on the same corridor. The volume of traffic on the IT corridor is more than 5 Lakh vehicles on weekdays. Residents and employees of firms have been waiting for more than two years for road improvements. Rajiv Gandhi road is having nine major intersections in which maximum congestion and delay occurred at Madhya Kailash, Tidel park and at SRP Tools intersection which is taken as study area.

It is a highway with six lane of width $25 \mathrm{~m}$ and $5.6 \mathrm{~km}$ long. During 17.00 to 21.00 hours the volume of vehicle flow is very high. It takes about 25 minutes to travel for about $4.1 \mathrm{kms}(9.84 \mathrm{kmph})$ during the peak period. The peak flow occurs between 17.30$18.30 \mathrm{hrs}$ at Madhya kailash intersection (2321 PCE) and the same occur between 20-21 hrs at other two intersections (2544 PCE at Tidel park and 2396 PCE at SRP Tools). The volume to capacity ratio at all three intersections are greater than one, which need immediate improvement measure. To improve the flow, as a long term measure, a trumpet interchange was proposed at Madhya kailash intersection by TNRDC but this proposal had been reject- 
ed by the State Government - as it felt land acquisition would be a problem and the facility could possibly be a disturbance to educational institutions located nearby. As an alternate to this proposal the existing flyover from Gandhi Mandapam on Sardar Patel road can be extended up to Madhya Kailash and it may descends on Rajiv Gandhi road towards South will drags the peak volume to 1725 PCE and the volume to capacity will come down to 0.95 .

As a short-term management measure diversion of vehicles towards South at the Madhya Kailash intersection has to turn South as one-way movement in the before point near Adyar student Xerox and run through first avenue, $8^{\text {th }}$ avenue, $28^{\text {th }}$ and $29^{\text {th }}$ cross streets and enters to ECR near Poondi Amman koil to reach Tidel park will drags 392 PCEs and the volume to capacity ratio comes down to lesser than 1 . As a further management measure, by diverting the vehicles towards North at SRP Tools intersection, to the West via Tharamani road to reach Sardar Patel road will bring down 372 PCE and the peak volume will comes down to 2024 PCE. The diverted traffic via Tharamani road has to pass through VV Koil street towards North, CSIR road towards West, Pillaiyar koil street towards North, Kalikunram main road towards North, Pallipattu main road towards North and Sriram Nagar main road towards North to reach Sardar Patel road. The long and short term management measures at Madhya Kailash, Tidel park and SRP Tools intersection will improve the flow of vehicles and will sustain at-least for the next couple of years along Rajiv Gandhi road.

\section{Acknowledgement}

This is a text of acknowledgements. Do not forget people who have assisted you on your work. Do not exaggerate with thanks. If your work has been paid by a Grant, mention the Grant name and number here.

\section{References}

[1] Highlights Of The Recommendations Of The State Level Committee On Road Connectivity \& Traffic Improvements In Chennai (2008) P7 Available At Http://Www.Cmdachennai.Gov. In /Highlights_Hlc0901200913-1-09.Pdf

[2] The Hindu (09/11/2016), "Implications Of Changes On Rajiv Gandhi Roadtools", Reported By Deepa H Ramakrishnan And K. Lakshmi, Available At Http://Www. Thehindu. Com/News/ Cities/ Chennai/ Implications-Of-Changes-On-Rajiv-Gandhi-Roadtools/ Article12079684.Ece

[3] The Hindu, Oppili (2004), "Traffic Goes Haywire As Lorry Overturns On Sardar Patel Road", Available At Http:/ Www.Thehindu.Com/ 2004/07/23 /Stories/ 2004072312900 300.Htm

[4] Manuj Darbari, Sanjay Medhavi And Abhay Kumar Srivastava (2008), "Development Of Effective Urban Road Traffic Management Using Workflow Wechniques For Upcoming Metro Cities Like Lucknow (India)", Ij.Of Hybrid Information Technology, Vol 1, No. 3, Pp99-107.

[5] Bhargavi P.S And N. Kannaiya Raja (2011), "A Study On The Effective Traffic Management Of Roads To Reduce Road Accidents In Tamilnadu", Ij.Of Enterprise Innovation Management Studies (Ijeims), Vol.2. No2, Pp172-190.

[6] Amudapuram Mohan Rao and Kalaga Ramachandra Rao (2012), "Measuring Urban Traffic Congestion - A Review", Ij. For Tra-C and Transport Engineering, 2012, 2(4): 286 - 305, Available At Http://Web.Iitd. Ac.In/ Rrkalaga/Pubs/Ijtte_2012-Congestion.Pdf

[7] Takayuki Kishii (2016), "Tunnelling and Underground Space Technology Incorporating Trenchless Technology Research", International Tunnelling Association, Utilization Of Underground Space In Japan, Vol.55 Pp 320-323

[8] Absar Alam.M And Faisal Ahmed (2013), "Urban Transport Systems And Congestion: A Case Study Of Indian Cities", Transport And Communications Bulletin For Asia And The Pacific No. 82, Available Http://Www.Unescap.Org/Sites/Default/Files/Bulletin82_Article3.Pdf
[9] Jian Sheng Yeung and Yiik Diew Wong (2013), "Road Traffic Accidents in Singapore Expressway Tunnels", Tunnelling And Underground Space Technology, Available At Https:// Scinapse.Io/Papers/ 1979358709/Cited

[10] Aparajita Chakrabartty And Sudakshina Gupta (2014), "Traffic Congestion In The Metropolitan City Of Kolkata", Jl. Of Infrastructure Development, Vol. 6, Issue 1, Pp43-59.

[11] Sampathkumar V, Siva Shankar S And Vishaka Murthy P (2014), "Intersection Improvement At Sholinganallur In Rajiv Gandhi Road”, Indian J1. Of Applied Research, Vol. 4, Issue 5, Pp213215, Issn - 2249-555x.

[12] Tadashiitoh (2014), "Hedonic Estimates Of The Underground Tunnels Of Mittlerer Ring", Mobil. Tum 2014 "Sustainable Mobility In Metropolitan Regions”, May 19-20, 2014, Tadashi Itoh / Transportation Research Procedia 4 ( 2014 ) 407 - 420.

[13] Dimitris Kaliampakos, Andreas Benardos And Athanassios Mavrikos (2015), "A Review On The Economics Of Underground Space Utilization", Tunnelling And Underground Space Technology 55, Doi 10.1016/J.Tust.2015.10.022 Available At Https://Www.Researchgate.Net/ Publication/ 284077558 A Review On The_Economics Of_Underground_Space_Utilization

[14] Yangyang, Tiezhuli, Taozhang And Qianyu (2017), “A Methodology For Evaluating Evacuation Capacity Of Urban Under Ground Road", Transportation Research Procedia, Vol. 25, Pp 1690-1706.

[15] Tnn Updated (Feb 7, 2018), "New Signal On Omr Of No Use, Complain Locals", Available At Https://Timesofindia.Indiatimes.Com/City/Chennai/New-SignalOn-Omr-Of-No-Use-Complain-Locals/Articleshow/62 811481.Cms

[16] From Wikipedia (2017), "Madhya Kailash Junction", Available At Https://En.Wikipedia. Org /Wiki/ Madhya Kailash Junction. 